\title{
Análise de fatores ambientais em marcenarias no Distrito Federal ${ }^{1}$
}

\author{
Nilton C. Fiedler ${ }^{2}$, Fábio Venturoli ${ }^{3}$ \& Luciano J. Minetti ${ }^{4}$
}

\begin{abstract}
RESUMO
Esta pesquisa foi realizada em marcenarias localizadas no Distrito Federal cujo objetivo foi analisar a exposição dos trabalhadores de marcenarias aos fatores ambientais como conforto térmico e iluminância, e fornecer subsídios para uma organização ou reorganização ergonômica do trabalho, visando à melhoria da saúde, segurança, bem-estar, conforto, satisfação, qualidade e produtividade do trabalho. As máquinas escolhidas para a análise foram serra circular esquadrejadeira, tupia, desempenadeira, furadeira horizontal e lixadeira de cinta. Os dados foram coletados ao longo da jornada de trabalho pelas medições do Índice de Bulbo Úmido e Termômetro de Globo (Índice de Bulbo Úmido e Termômetro de Globo) e de iluminância do ambiente de trabalho. Realizaram-se análises de variâncias para verificar se houve diferenças significativas entre os valores coletados. Os resultados indicaram que o IBUTG médio encontrado nas empresas foi de $21,4{ }^{\circ} \mathrm{C}$, o que permite um trabalho contínuo durante as $8 \mathrm{~h}$ da jornada, segundo a NR 15 . Alguns postos de trabalho apresentaram deficiências com relação à iluminância, segundo a NBR 5413/92, tupia (467 LUX) e furadeira horizontal (390 LUX) na empresa 2, serra circular esquadrejadeira (179 LUX) e lixadeira de cinta (172 LUX) na empresa 3 e tupia (339 LUX) na empresa 4.
\end{abstract}

Palavras-chave: ergonomia, avaliação ergonômica, ambiente de trabalho

\section{Analysis of environmental factors in joinery in the Federal District of Brazil}

\begin{abstract}
This research was carried out in four joineries located in the Federal District of Brazil, with the objective to analyze the exposition of the workers of joineries to the ambient factors - thermal comfort and illumination and to supply subsidies for an organization or ergonomic reorganization of the work, aiming the improvement of the health, security, well-being, comfort, satisfaction, quality and productivity of the work. The machines chosen for the analysis had been the buzz saw of stand, tupia, float, horizontal wimble and sander of brace. The data were collected along the working period, through climatic measurements of the illumination and work environment. Analyses of variance of the climatic conditions and illumination were performed in order to verify if there were significant differences between the values collected. The results indicated that the joined average Índice of wet bulb and globe temperature in the companies was $21.4{ }^{\circ} \mathrm{C}$, which allows a continuous work during the $8 \mathrm{~h}$ of the day, according to NR 15. Some places of work presented deficiencies with relation to the illumination, according to NBR 5413/92, tupia (467 LUX) and horizontal wimble (390 LUX) in company 2, buzz saw of stand (179 LUX) and sander of brace (172 LUX) in company 3 and tupia (339 LUX) in company 4.
\end{abstract}

Key words: ergonomy, ergonomic evaluation, work environment

${ }^{1}$ Trabalho realizado com apoio do CNPq

${ }^{2}$ Depto Eng. Florestal/CCA/UFEAS, Av. Carlos Lindemberg, s/n, CEP 29550-000, Jerônimo Monteiro, ES. E-mail: fiedler@cca.ufes.br

3 Doutorando em Ciencias Florestais/UNB, CEP 70910-900, Brasília. Fone: (61) 3307-2700. E-mail: venturoli@unb.br

${ }^{4}$ Depto. de Engenharia Elétrica e de Produção/UFV, Campus Universitário, CEP: 36570-000, Viçosa-MG. Fone: (31) 3899-2721. E-mail: minetti@ufv.br 


\section{INTRODUÇÃO}

Existe atualmente, grande preocupação com a associação entre o ambiente laboral e as condições ambientais básicas. A necessidade de integração entre o ambiente de trabalho (fatores ambientais), seu entorno e a vida na cidade, vem-se manifestando em formulações doutrinárias e na prática empresarial (Milaré, 2000).

A segurança, o conforto ambiental e os espaços para convivência social, são pontos essenciais no interior de uma empresa. Das modificações que venham a ser realizadas, deve-se levar em consideração as opiniões e demandas dos trabalhadores, já que eles são as pessoas mais afetadas pelo ambiente de trabalho (Ministério da Saúde, 2001).

Segundo Alvarez (1996) as características de um ambiente de trabalho refletem, de maneira expressiva, as qualidades do trabalhador. Um local de trabalho deve ser sadio e agradável, que proporcione o máximo de proteção, sendo o resultado de fatores materiais ou subjetivos, e deve prevenir acidentes, doenças ocupacionais, além de proporcionar melhor relacionamento entre a empresa e o empregado.

Entre os diversos fatores ambientais que interagem com os trabalhadores em marcenarias, destacam-se o conforto térmico e a iluminância.

Do ponto de vista térmico, a medida em que o meio se torna hostil, maiores serão as exigências de termorregulação. O trabalhador, instintivamente, procura melhorar seu conforto, o que pode afetar sua atenção durante a atividade específica que está realizando e favorecer, assim, a distração e as conseqüentes perdas de eficiência e segurança no trabalho (Couto, 1995). Conforto térmico, segundo Rivero (1986), relaciona seis variáveis principais: a atividade, a vestimenta, a temperatura média radiante, a temperatura, a velocidade e a umidade do ar.

A temperatura é um indício do fluxo de calor que exprime o grau de calor ou frio num lugar ou num corpo, cujas sensações produzidas no corpo humano são dependentes do grau de umidade do ar ambiente e da velocidade do vento (Minetti et al., 1998).

Conforme Verdussen (1978), a temperatura é um ponto que deve merecer o maior cuidado quando se busca criar condições ambientais de trabalho adequadas; há temperaturas que oferecem sensação de conforto, enquanto outras promovem sensações desagradáveis e até prejudiciais à saúde. Ainda segundo o autor, em ambientes de temperatura elevada ocorre redução na velocidade das reações e diminuição da agilidade mental, o que aumenta a possibilidade de acidentes, além de afetar significativamente o rendimento.

Quando o homem é obrigado a suportar altas temperaturas, seu rendimento cai, a velocidade do trabalho diminui, as pausas se tornam maiores e mais freqüentes, o grau de concentração diminui e a freqüência de erros e de acidentes tende a aumentar significativamente, sobretudo a partir dos $30^{\circ} \mathrm{C}$.

Conforto visual, segundo Lamberts et al. (1997), é entendido como a existência de um conjunto de condições em determinado ambiente, no qual o ser humano pode desenvol- ver suas tarefas visuais com o máximo de acuidade (medida da habilidade do olho humano em discernir detalhes) e precisão visual.

A claridade do ambiente de trabalho é determinada não apenas pela intensidade da luz mas, também, pelas distâncias e pelo índice de reflexão das paredes, teto, piso, máquinas e mobiliário. Um bom sistema de iluminação, com uso adequado de cores e a criação de contrastes, pode produzir um ambiente agradável, onde as pessoas trabalhem confortavelmente, com pouca fadiga, monotonia e acidentes, produzindo com maior satisfação (Iida, 1990).

Quando a luz emitida por uma fonte atinge uma superfície, esta será iluminada; assim, iluminância (E), é a medida da quantidade de luz incidente numa superfície por unidade de área; sua unidade é lúmen $\mathrm{m}^{-2}$ ou lux (lx) (Santos, 2002).

Desta pesquisa teve-se, como objetivo, analisar a exposição dos trabalhadores de marcenarias no Distrito Federal aos fatores ambientais conforto térmico e iluminância e, desta forma, fornecer subsídios para uma organização ou reorganização ergonômica do trabalho visando à melhoria qualidade do trabalho.

\section{MATERIAL E MÉTODOS}

\section{Região de estudo}

O estudo foi desenvolvido em quatro marcenarias no Distrito Federal no período de julho de 2001 a julho de 2002. As empresas foram escolhidas aleatoriamente a partir de um diagnóstico à Secretaria da Fazenda do Governo do Distrito Federal, Sindicato das Indústrias de Madeira e do Mobiliário do Distrito Federal (SINDIMAM) e Federação das Indústrias de Brasília (FIBRA).

\section{População, amostragem e modelo estatístico}

As avaliações nos postos de trabalho foram realizadas em quatro empresas, tendo sido analisadas seis máquinas mais comuns a todas as empresas e por serem as principais máquinas envolvidas no processo de fabricação de móveis, que são a serra circular esquadrejadeira, a tupia, a desempenadeira, desengrossadeira, a furadeira horizontal e a lixadeira de cinta, caracterizadas de acordo com o Serviço Nacional de Aprendizagem Industrial SENAI (1987) Tabela 1.

Para a avaliação do conforto térmico considerou-se um delineamento inteiramente casualizado, com diferentes números de repetições, seguindo-se o modelo estatístico descrito por Searle (1971) e Neter \& Wasserman (1974), Eq. 1.

$$
\mathrm{Y}_{\mathrm{ij}}=\mu+\mathrm{t}_{\mathrm{i}}+\mathrm{e}_{\mathrm{ij}}
$$

em que:

$$
\begin{aligned}
Y_{i j} & \text { - observação referente à empresa i na repetição j } \\
\mu & \text { - média geral } \\
t_{i} & \text { - efeito da empresa i (fixo) } \\
e_{i j} & \text { - erro aleatório ou resíduo }
\end{aligned}
$$


Tabela 1. Descrição técnica das máquinas avaliadas

\begin{tabular}{ll}
\hline \multicolumn{1}{c}{ Máquina } & \multicolumn{1}{c}{ Descrição } \\
Serra circular esquadrejadeira & $\begin{array}{l}\text { Utilizada para serrar madeira ou derivados em cortes retos, por meio de uma serra circular dentada acoplada a uma mesa de corpo } \\
\text { fixo e um carrinho para movimentar a peça a ser cortada. }\end{array}$ \\
Tupia & $\begin{array}{l}\text { Utilizada para fazer molduras, rebaixamentos, ranhuras, perfis e canais. Composta por uma base de ferro na qual se apóia um tampo, } \\
\text { no centro do qual há um eixo onde se prendem as ferramentas de corte, que giram à alta velocidade (4000 a 8000 rpm). }\end{array}$ \\
Desempenadeira & Utilizada para nivelar a superfície da peça. \\
Vesengrossadeira & $\begin{array}{l}\text { Visa dimensionar a espessura das peças. Utilizada também na operação de desbaste, para aplainar superfícies, tornando-as } \\
\text { uniformes. É constituída por uma base de ferro fundido e possui na parte superior uma capa de proteção cobrindo o eixo, o qual } \\
\text { é constituído por navalhas e dois rolos de alimentação, que funcionam automaticamente. No nível da mesa estão dispostos outros } \\
\text { dois rolos lisos que servem para o deslize da madeira }\end{array}$ \\
Furadeira horizontal & Utilizada para fazer furos e cavas, em peças de madeira, e encaixes de espigas ou cavilhas \\
Lixadeira de cinta & $\begin{array}{l}\text { Acabamentos de superfícies planas ou curvas. Elimina imperfeiçóes e asperezas para que a peça possa receber o acabamento } \\
\text { final. Compõe-se de duas colunas ligadas entre si por uma cinta de lixa, entre as quais existe uma mesa fixa onde é apoiada a } \\
\text { peça de madeira. }\end{array}$ \\
\hline
\end{tabular}

Fonte: SENAI (1987)

Para a avaliação da condição de iluminância, considerouse um modelo fatorial inteiramente casualizado cujos fatores foram máquinas e empresas e diferentes repetições, segundo o modelo estatístico apresentado por Searle (1971) e Neter \& Wasserman (1974), Eq. 2.

$$
Y_{i j}=\mu+a_{i}+b_{j}+(a x b)_{i j}+e_{i j}
$$

em que:

$\mathrm{Y}_{\mathrm{ij}}$ - Observação referente à máquina i na empresa j

$\mu$ - média geral

$\mathrm{a}_{\mathrm{i}}$ - efeito da máquina i (fixo)

$b_{j}$ - efeito da empresa j (fixo)

$(\mathrm{axb})_{\mathrm{ij}}$ - efeito da interação máquina e empresa (fixo)

$\mathrm{e}_{\mathrm{ij}}$ - erro aleatório ou resíduo

As médias foram comparadas pelo teste de Student-Newman-Keuls, a 5\% de probabilidade.

As condições climáticas do ambiente de trabalho foram avaliadas através de um termômetro digital de IBUTG da marca Wibget, modelo RSS-214, posicionado no centro dos galpões à altura do tórax dos trabalhadores.

A iluminância foi medida por um luxímetro digital portátil, modelo LX 101, da marca Lutron.

Ambas as leituras foram efetuadas sistematicamente a cada duas horas, durante toda a jornada de trabalho, pelo período de 12 meses, em que a primeira leitura foi feita às 9 horas e a última às $17 \mathrm{~h}$, conforme metodologia utilizada por Minetti (1996) e Norma NBR 5413/92 (ABNT, 2005).

A legislação brasileira, por meio da Norma Regulamentadora 15 (NR 15) para atividades e operações insalubres (Ministério do Trabalho e Emprego, 2005), estabelece que:

1. A exposição ao calor deve ser avaliada através do "Índice de Bulbo Úmido e Termômetro de Globo (IBUTG)” definido pelas Eqs. 3 e 4.

Em ambientes internos ou externos sem carga solar:

$$
\text { IBUTG }=0,7 \mathrm{tbn}+0,3 \mathrm{tg}
$$

Em ambientes externos com carga solar:

$$
\text { IBUTG }=0,7 \mathrm{tbn}+0,1 \mathrm{tbs}+0,2 \mathrm{tg}
$$

em que:

$$
\begin{aligned}
& \text { tbn - temperatura de bulbo úmido natural } \\
& \text { tg - temperatura de globo (considera o efeito da ra- } \\
& \text { diação) } \\
& \text { tbs - temperatura de bulbo seco }
\end{aligned}
$$

2. Os aparelhos que devem ser usados nesta avaliação, são: termômetro de bulbo úmido natural, termômetro de globo e termômetro de mercúrio comum.

3. As medições devem ser efetuadas no local onde permanece o trabalhador, à altura da região do corpo mais atingida.

Em função do índice obtido, o regime de trabalho intermitente será definido conforme a Tabela 2.

A quantidade de luz necessária depende da atividade a ser

\begin{tabular}{|c|c|c|c|}
\hline \multirow{2}{*}{$\begin{array}{l}\text { Regime de trabalho intermitente } \\
\text { com descanso no próprio local de } \\
\text { trabalho } \\
\text { (por hora) }\end{array}$} & \multicolumn{3}{|c|}{ Tipo de atividade ( $\left.{ }^{\circ} \mathrm{C}\right)$} \\
\hline & Leve & Moderada & Pesada \\
\hline Trabalho contínuo & até 30,0 & até 26,7 & até 25,0 \\
\hline $\begin{array}{l}45 \text { minutos trabalho } \\
15 \text { minutos descanso }\end{array}$ & 30,1 a 30,6 & 26,8 a 28,0 & 25,1 a 25,9 \\
\hline $\begin{array}{l}30 \text { minutos trabalho } \\
30 \text { minutos descanso }\end{array}$ & 30,7 a 31,4 & 28,1 a 29,4 & 26,0 a 27,9 \\
\hline $\begin{array}{l}15 \text { minutos trabalho } \\
45 \text { minutos descanso }\end{array}$ & 31,5 a 32,2 & 29,5 a 31,1 & 28,0 a 30,0 \\
\hline $\begin{array}{l}\text { Não é permitido o trabalho sem a } \\
\text { adoção de medidas adequadas de } \\
\text { controle }\end{array}$ & $\begin{array}{l}\text { acima } \\
\text { de } 32,2\end{array}$ & $\begin{array}{l}\text { acima } \\
\text { de } 31,1\end{array}$ & $\begin{array}{l}\text { acima de } \\
30\end{array}$ \\
\hline
\end{tabular}
executada. A NBR 5413/92 (ABNT, 2005) regulamenta que em atividades de trabalho bruto de maquinaria, como no caso da maioria dos postos de trabalho nas marcenarias, o índice de iluminância deve estar no mínimo entre 200 e 500 LUX.

Tabela 2. Limites de tolerância para exposição ao calor em função do IBUTG

Fonte: NR 15 (Ministério do Trabalho e Emprego, 2005). 
Tabela 3. Índices de iluminância por grupo de tarefas visuais

\begin{tabular}{lcl}
\hline \multicolumn{1}{c}{ Faixa } & $\begin{array}{c}\text { Iluminância mínima } \\
\text { (Lux) }\end{array}$ & \multicolumn{1}{c}{ Tipo de atividade } \\
A & $20-50$ & Áreas públicas com arredores escuros \\
Illuminação geral para áreas com tarefas & $50-100$ & Orientação simples para permanência curta \\
visuais simples & $100-200$ & Recintos não usados para trabalho contínuo \\
& $200-500$ & Tarefas com requisitos visuais limitados, trabalho bruto de maquinaria, auditórios \\
B & $500-1000$ & Tarefas com requisitos visuais normais, trabalho médio de maquinaria, escritórios \\
Iluminação geral para áreas de trabalho & $1000-2000$ & Tarefas com requisitos especiais, gravação manual, inspeção, indústria de roupas \\
& $2000-5000$ & Tarefas visuais exatas e prolongadas, eletrônica de tamanho pequeno, relógios \\
C & $5000-10000$ & Tarefas visuais muito exatas, montagem de microeletrônica \\
lluminação adicional para tarefas visuais & $10000-20000$ & Tarefas visuais muito especiais, cirurgia \\
\hline difíceis &
\end{tabular}

Fonte: NBR 5413/92.

Na Tabela 3 consta os índices de iluminância necessários por grupo de tarefas visuais.

\section{RESULTADOS E DISCUSSÃO}

\section{Conforto térmico}

O IBUTG médio encontrado nas empresas foi de $21,4{ }^{\circ} \mathrm{C}$. Por outro lado, os resultados referentes à análise de variância para o conforto térmico são apresentados na Tabela 4, verificando-se que não houve diferença significativa a $1 \%$ de probabilidade, entre as empresas estudadas.

Tabela 4. Análise de variância para o conforto térmico durante a jornada de trabalho

\begin{tabular}{lrrrc}
\hline \multicolumn{1}{r}{ FV } & GL & SQ & QM & F \\
Empresa & 3 & 17,57 & 5,75 & $1,7749^{\text {ns }}$ \\
Resíduo & 153 & 503,51 & 3,29 & \\
Total & 156 & 521,08 & 9,04 & \\
\hline
\end{tabular}

ns não significativo a $1 \%$ de probabilidade

Para uma visualização melhor do IBUTG fez-se, durante toda a jornada de trabalho, uma aproximação por intervalo de confiança (IC), de modo que fosse apresentada a amplitude de variação do IBUTG nas empresas dentro do nível de confiança de $95 \%$, que forneceu os valores de IC $=\left[21,11^{\circ} \mathrm{C} \leq \mathrm{X} \leq 21,73^{\circ} \mathrm{C}\right]$

Estudos já realizados por diversos autores (Minetti et al., 1998, Silva, 1999, Fiedler et al., 2001) indicaram que a variação climática aumenta ou diminui, conforme o movimento do sol, sendo os horários das $9 \mathrm{~h}$ e das $17 \mathrm{~h}$ os de mais baixas temperaturas, em função do início e do término do dia, respectivamente e o horário das 13 o de temperaturas mais elevadas. Deste modo, 95\% representam o percentual de confiabilidade de que no horário em que possivelmente ocorreu o maior IBUTG, este não ultrapassou a marca dos $21,73^{\circ} \mathrm{C}$ sendo, portanto, tolerado perfeitamente pelo organismo humano para a realização das tarefas nas atividades de fabricação de móveis.

A Figura 1 apresenta os valores médios de IBUTG encontrados nas quatro empresas analisadas.

De acordo com o intervalo de confiança gerado, pode-se afirmar que as empresas estavam enquadradas na norma

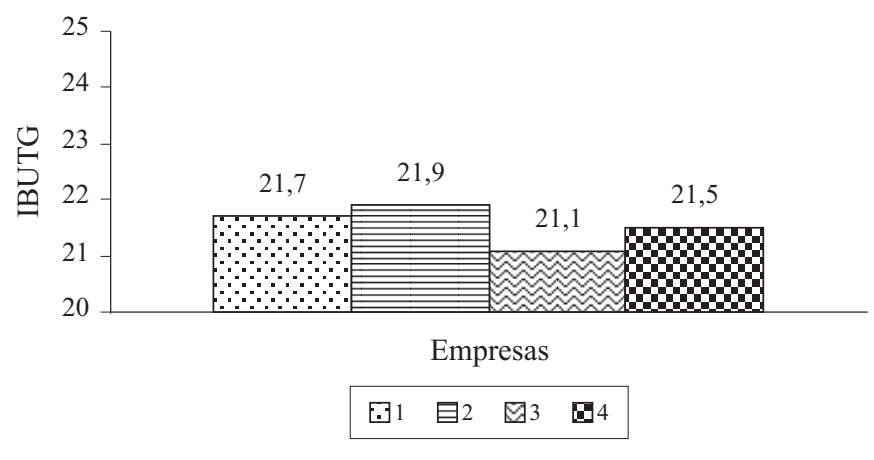

Figura 1. Valores médios de IBUTG encontrados nas marcenarias avaliadas

NR15 do Ministério do Trabalho e Emprego (Ministério do Trabalho e Emprego, 2005), que preceitua que qualquer trabalho, contínuo ou não, pode ser realizado até um limite de $25^{\circ} \mathrm{C}$ de IBUTG sem dano à saúde humana; portanto, o trabalho estava sendo realizado sob condições seguras e a favor do rendimento e produtividade do trabalhador.

\section{Iluminância}

A iluminância média encontrada nas empresas foi de 614 LUX. Os resultados referentes à análise de variância para as máquinas e empresas, são apresentados na Tabela 5, na qual se constatou a existência de interação significativa entre as máquinas e empresas sendo necessário, portanto, um desdobramento do estudo para analisar o comportamento de cada fator na presença do outro.

Tabela 5. Análise de variância para a iluminância no ambiente das máquinas analisadas

\begin{tabular}{lcccc}
\hline \multicolumn{1}{c}{ FV } & GL & SQ & QM & F \\
Empresa & 3 & $0,207 \times 10^{8}$ & 6920826 & $35,048^{* *}$ \\
Máquina & 5 & $0,225 \times 10^{8}$ & 4516595 & $22,873^{* *}$ \\
Empresa x máquina & 15 & $0,813 \times 10^{8}$ & 5424677 & $27,471 * *$ \\
Resíduo & 954 & $0,188 \times 10^{9}$ & 197468,2 & \\
Total & 977 & $3,13 \times 10^{8}$ & 17059566,2 & \\
\hline
\end{tabular}

** Significativo a $1 \%$ de probabilidade

Para a decomposição da interação máquina x empresa, fez-se uma análise de variância para estudar o efeito de máquinas nas diferentes empresas, cujos resultados são apresentados na Tabela 6. 
Tabela 6. Análise de variância para o estudo das máquinas dentro das empresas

\begin{tabular}{lcccc}
\hline \multicolumn{1}{c}{ FV } & GL & SQ & QM & F \\
Empresa & 3 & $0,207 \times 10^{8}$ & 6920826 & $35,048^{* *}$ \\
Maq./Empr.1 & 5 & $0,689 \times 10^{8}$ & $0,137 \times 10^{8}$ & $20,792^{* *}$ \\
Maq./Empr.2 & 5 & 8246154 & 1649231 & $16,341^{* *}$ \\
Maq./Empr.3 & 5 & $0,180 \times 10^{8}$ & 361,8463 & $59,949^{* *}$ \\
Maq./Empr.4 & 5 & 5561748 & 1112350 & $36,341^{* *}$ \\
Resíduo & 954 & $0,188 \times 10^{9}$ & 197468,2 & \\
Total & 977 & $3,13 \times 10^{8}$ & 17059566,2 & \\
\hline ** & & & &
\end{tabular}

** Significativo a nível de $1 \%$ de probabilidade.

Pelos resultados apresentados na Tabela 6, ficou evidenciado que houve diferença significativa a $1 \%$ de probabilidade entre os postos de trabalho, em todas as empresas; assim sendo, utilizou-se o teste de comparação de médias para verificar quais as iluminâncias nos postos de trabalho diferiram estatisticamente entre si. Os resultados são mostrados na Tabela 7.

De acordo com os resultados (Tabela 7), na empresa 1 a iluminância do posto de trabalho na tupia diferiu estatisticamente de todas as demais máquinas. A furadeira horizontal, a desengrossadeira, a desempenadeira e a serra circular esquadrejadeira, apresentaram ambientes com índices de iluminância não diferentes entre si estatisticamente, tendo a condição de iluminância na furadeira horizontal diferido da verificada na lixadeira de cinta.

Quando se analisaram os dados referentes ao posto de trabalho de cada máquina na empresa 1 , a única máqui-

Tabela 7. Teste de comparações de médias de Student-Newman-Keuls para a iluminância do posto de trabalho nas máquinas

\begin{tabular}{|c|c|c|}
\hline Empresa & Máquina & Média LUX \\
\hline \multirow{6}{*}{1} & Tupia & 1999a \\
\hline & Furadeira horizontal & $1000 \mathrm{~b}$ \\
\hline & Desengrossadeira & $810 \mathrm{bc}$ \\
\hline & Desempenadeira & $614 b c$ \\
\hline & Serra circular esquadrejadeira & $476 \mathrm{bc}$ \\
\hline & Lixadeira de cinta & $280 c$ \\
\hline \multirow{6}{*}{2} & Serra circular esquadrejadeira & $978 \mathrm{a}$ \\
\hline & Desempenadeira & $700 \mathrm{~b}$ \\
\hline & Desengrossadeira & $660 \mathrm{bc}$ \\
\hline & Lixadeira de cinta & $602 b c$ \\
\hline & Tupia & $467 \mathrm{~cd}$ \\
\hline & Furadeira horizontal & $390 d$ \\
\hline \multirow{6}{*}{3} & Furadeira horizontal & $991 \mathrm{a}$ \\
\hline & Desempenadeira & $684 b$ \\
\hline & Desengrossadeira & $573 b c$ \\
\hline & Tupia & $509 c$ \\
\hline & Serra circular esquadrejadeira & $179 d$ \\
\hline & Lixadeira de cinta & $172 d$ \\
\hline \multirow{6}{*}{4} & Serra circular esquadrejadeira & $626 a$ \\
\hline & Desengrossadeira & $610 \mathrm{a}$ \\
\hline & Desempenadeira & $590 a$ \\
\hline & Furadeira horizontal & $480 \mathrm{~b}$ \\
\hline & Tupia & $339 c$ \\
\hline & Lixadeira de cinta & $276 c$ \\
\hline
\end{tabular}

Médias seguidas pela mesma letra, em cada empresa, não diferem estatisticamente a $5 \%$ de probabilidade na que apresentou ambiente com iluminância abaixo do limite mínimo exigido pela Norma NBR 5413/92, foi a lixadeira de cinta, em que se estimou, em alguma hora do dia, haver apresentado valores próximos a 151 LUX; abaixo, portanto, do exigido pela norma citada: IC $=[151,20 \mathrm{LUX} \leq \mathrm{X} \leq 409,06 \mathrm{LUX}]$ a 95\% de probabilidade. Todas as outras máquinas apresentaram ambientes com índices de iluminância que se enquadraram nos limites mínimos exigidos pela NBR 5413/92.

Os resultados indicados na Tabela 7 , referentes à empresa 2, permitiram afirmar que o ambiente da serra circular esquadrejadeira diferiu estatisticamente dos demais. A iluminância nos postos de trabalho da desempenadeira, da desengrossadeira e da lixadeira de cinta, não diferiu estatisticamente entre si; já a iluminância no posto de trabalho dessas duas últimas não diferiu estatisticamente da tupia, que também não diferiu da furadeira horizontal.

Os resultados indicaram que a empresa 2 não estava em desacordo com os valores mínimos exigidos pela NBR $5413 / 92$, exceto nos casos da furadeira horizontal e da tupia que por serem máquinas de trabalho que exigem maior atenção, de acordo com esta norma, deveriam estar em um ambiente com iluminância mínima de 500 LUX, e os valores médios encontrados foram, respectivamente, de 390 LUX e 467 LUX.

Os postos de trabalho na empresa 3 não estavam, de maneira geral, com o nível de iluminância abaixo do mínimo exigido pela NBR 5413/92. Pela análise da Tabela 7 ficou evidenciado que o posto de trabalho da furadeira horizontal apresentou valores estatísticos diferentes das demais máquinas. Na desempenadeira e na desengrossadeira não foram encontrados valores estatisticamente diferentes entre si. O posto de trabalho da desengrossadeira não diferiu estatisticamente do da tupia. A serra circular esquadrejadeira e a lixadeira de cinta apresentaram condições de iluminância estatisticamente não diferentes entre si mas, sim, do ambiente das demais máquinas. Os ambientes da lixadeira de cinta e da serra circular esquadrejadeira foram os únicos nesta empresa cuja iluminância estava em desacordo com a Legislação Trabalhista Brasileira (NBR 5413/92). Casos em que os operadores devem atentar para o trabalho para evitar acidentes, ante os riscos provocados pela má iluminância no posto de trabalho. Os responsáveis pela empresa devem tomar decisões para resolver o problema, seja com iluminação localizada, aberturas laterais, limpeza e posicionamento de janelas, mudança no tipo de cobertura ou o deslocamento dessas máquinas para locais mais iluminados.

De maneira geral, a empresa 4 não apresentou problemas quanto a iluminância no ambiente de trabalho durante a jornada de trabalho. Pela análise da Tabela 7 é possível afirmar que os postos de trabalho da serra circular esquadrejadeira, da desengrossadeira e da desempenadeira, não diferiram estatisticamente entre si. A condição de iluminância no posto de trabalho da tupia não diferiu do posto de trabalho da lixadeira de cinta, mas estes diferiram estatisticamente do posto de trabalho das demais máquinas.

$\mathrm{O}$ posto de trabalho da furadeira horizontal diferiu 
estatisticamente das outras máquinas e não se enquadrava na norma NBR 5413/92, pois indicou iluminância média de 480 LUX. A tupia também não se enquadrou na norma, pois apresentou iluminância média de 339 LUX, quando o mínimo exigido para essas duas máquinas é de 500 LUX, conforme NBR 5413/92.

\section{Análise da iluminância nos postos de trabalho}

O fato de ocorrerem variações muito altas entre todas as empresas, evidencia oscilações de luminosidade no mesmo ambiente de trabalho e/ou a ocorrência de sombras na superfície de trabalho, exigindo maior esforço visual do operador, levando a uma baixa qualidade no trabalho, baixa produtividade, esforço visual e fadiga, além de propiciar a ocorrência de acidentes, já que os olhos humanos precisam de um tempo de recuperação e adaptação ao passarem de um ambiente mais escuro para um mais claro e vice-versa.

Constatou-se não haver um padrão das empresas com relação à iluminância nos postos de trabalho. A iluminância no ambiente de trabalho é facilmente influenciada pela arquitetura da indústria (quantidade de aberturas naturais e tipo de iluminação geral ou localizada e pelo tipo de lâmpadas utilizadas). Todas as empresas têm, como ambiente, de trabalho, um galpão com as máquinas dispostas de acordo com a seqüência operacional. O diferencial é exatamente o layout das empresas, a quantidade de aberturas naturais, o tipo de lâmpadas utilizadas, o posicionamento da iluminação (localizada ou geral), as janelas e a qualidade da manutenção de todo este sistema.

Os valores médios de iluminância encontrados no ambiente que envolveu cada máquina em cada empresa, são mostrados na Figura 2.

Pela análise da Figura 2, ficou claro que apenas algumas máquinas estavam localizadas em locais com níveis médios de iluminância abaixo dos valores mínimos exigidos pela Legislação Trabalhista Brasileira (NBR 5413/92); as quais foram: a serra circular esquadrejadeira na empresa 3 e a lixadeira de cinta, também na empresa 3 , a furadeira horizontal na empresa 2 e na empresa 4.

\section{CONCLUSÕES}

1. O estudo de caso evidenciou que, quando analisados os fatores de acordo com a média geral encontrada em cada empresa, os valores que indicaram não adequação às normas brasileiras, ficaram mascarados, comprometendo a confiabilidade dos resultados apresentados.

2. Em todas as empresas foram encontradas inadequações à Legislação Trabalhista Brasileira.

3. IBUTG médio encontrado nas empresas foi de $21,4{ }^{\circ} \mathrm{C}$, permitindo um trabalho contínuo durante as $8 \mathrm{~h}$ da jornada.

4. Alguns postos de trabalho apresentaram deficiências com relação à iluminância, tupia (467 LUX) e furadeira horizontal (390 LUX) na empresa 2, serra circular esquadrejadeira (179 LUX) e lixadeira de cinta (172 LUX) na empresa 3 e tupia (339 LUX) na empresa 4.

\section{LITERATURA CITADA}

Alvarez, B. R. Qualidade de vida relacionada à saúde de trabalhadores. Florianópolis: UFSC, 1996. Dissertação Mestrado

ABNT. Associação Brasileira de Normas Técnicas. http:// www.abnt.org.br. 31 Mai, 2005.

Couto, H. A. Ergonomia aplicada ao trabalho - O manual técnico da máquina humana. Belo Horizonte: Ergo Editora, 1995, 353 p.

Fiedler, N. C.; Venturoli, F.; Minetti, L. J. Análise ergonômica do ambiente de trabalho em empresas Fabricantes de móveis no Distrito Federal In: Congresso Latino Americano de Ergonomia, 6, e Congresso Latino Americano de Ergonomia, 6, 2001, Gramado. Anais... ABERGO, 2001. 40p.

Iida, I. Ergonomia; projeto e produção. São Paulo: Edgard Blucher, 1990. 465p.

Lamberts, R.; Philippi, P. C.; Mendes, N. Estudo do comportamento higrotérmico de material de construção: desenvolvimento de modelos para um código genérico de transferência de calor. Florianópolis: UFSC, 1997. 189p. Tese Doutorado

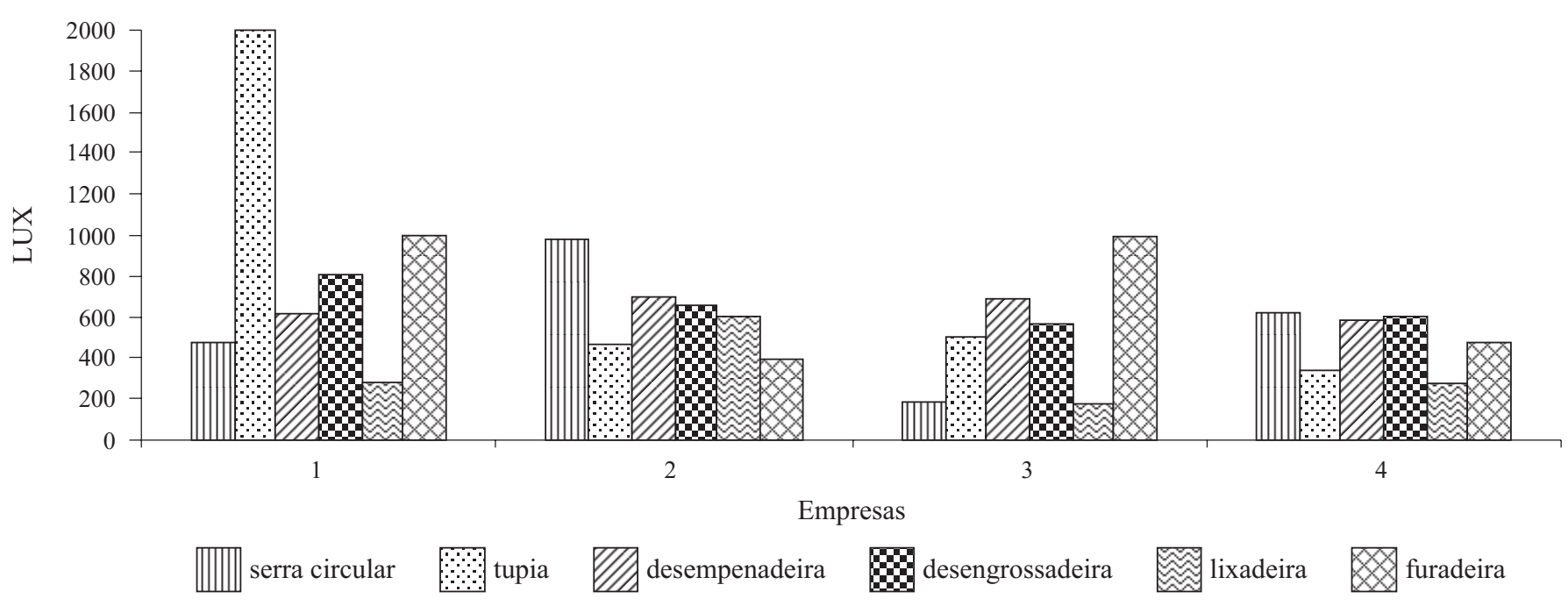

Figura 2. Valores médios de iluminância nos postos de trabalho de cada máquina por empresa 
Milaré, E. Direito do ambiente. São Paulo: Editora Revista dos Tribunais Ltda. 2000. 687p.

Minetti, L. J. Análise de fatores operacionais e ergonômicos na operação de corte florestal com motosserra. Viçosa: UFV, 1996. 211p. Tese Doutorado

Minetti, L. J.; Souza, A. P.; Machado, C. C.; Baêta, F. C.; Fiedler, N. C. Análise da influência de fatores climáticos no corte florestal com motosserra. Revista Árvore, Viçosa, v.22, n.4, p.527-534, 1998.

Ministério da Saúde - Universidade Federal de Minas Gerais (convênio). Programa Viva lelgal/TV Futura. Ambientes saudáveis a qualidade da empresa passa pela saúde do trabalhador. 2001.

Ministério do Trabalho e Emprego. Norma Regulamentora - NR 15 e 17 http://www.mte.gov.br. 10 julho 2005.

Neter, J.;Wasserman, W. Applied linear statistical models. Homewood: Richard D. Irwin, Inc. 842p. 1974.
Nimer, E. Climatologia do Brasil. Rio de Janeiro: IBGE, 1989.422p.

Rivero, R. Acondicionamento térmico natural - Arquitetura e clima. Porto Alegre: DCL, 1986. 240p.

Santos, N. Ergonomia e segurança industrial. http://www.eps.ufsc.br/ ergon/disciplinas/EPS5225. 22 agosto 2002.

Searle, S. R. Linear models. New York: John Wiley e Sons, Inc. 543p. 1971.

SENAI - Serviço Nacional de Aprendizagem Industrial - Curso sobre fabricação de móveis. Belo Horizonte: 1987. Módulos de curso.

Silva, K. R. Análise de fatores ergonômicos em marcenarias do município de Viçosa - MG. Viçosa: UFV, 1999. 97p. Dissertação Mestrado

Verdussen, R. Ergonomia: a racionalização humanizada do trabalho. Rio de Janeiro: Livros Técnicos e Científicos, 1978. 161p. 